\title{
Controlled nucleation and growth kinetics of lead nitrate phosphate in silica hydrogel and characterization of grown crystals
}

\author{
C C DESAI and M S V RAMANA \\ Department of Physics, Sardar Patel University, Vallabh Vidyanagar 388 120, India \\ MS received 23 January 1988; revised 5 April 1988
}

\begin{abstract}
Lead nitrate phosphate (LNP) single crystals were grown in silica hydrogel at an ambient temperature employing various nucleation control methods. The effect of concentration of feed solution, gel density, gel $\mathrm{pH}$, ageing of gels and temperature on reduction of nucleation centres is reported. Kinetic studies of the nucleation and growth of LNP crystals and dentrites were studied. The crystals are characterized by X-ray diffraction, density measurements, magnetic susceptibility, mechanical strength measurements and dissolution behaviour.
\end{abstract}

Keywords. Silica hydrogel; nucleation; gel density; gel ageing; growth kinetics; single crystal.

\section{Introduction}

In recent years, crystal growth in gel medium has attracted the attention of many investigators (Brenner et al 1966; Dennis and Henisch 1967; Armington and O'Conner 1967; Kratochvil et al 1968; Glockber and Soest 1969; Henisch 1970; Liow and Faust 1977) because of the following advantages compared to the free solution; (i) growth of the crystals has been nucleated without constraints, (ii) the growth proceeds at near ambient temperature, therefore the grown crystals contain less concentration of equilibrum defects and (iii) the possibility of dopant incorporation in large amount (Ruiz and Cintas 1985). But the main drawback is nucleation control. So far nothing has been reported regarding nucleation and growth kinetics of lead nitrate phosphate (LNP) single crystals in silica hydrogel. In the preliminary studies on growth of LNP single crystals, Brezina and Horvath (1982) reported the growth of these crystals in a cross-linked polyacrylamide gels after a long crystallization of four months.

LNP single crystals show many interesting physical properties such as ferroelectric, dielectric, piezoelectric, optical and other pertinent characteristics. They are used in transducers and in many linear and nonlinear mechanical devices. They are also apparently suitable for testing macroscopic theory of ferroelectricity. This paper demonstrates the technique of nucleation control in gels to obtain larger and more perfect LNP single crystals and to characterize the grown crystals. Observations made during the growth of dendritic crystals are also reported.

\section{Experimental procedure}

The silica gel (sodium meta silicate solution) was used as the growth media for this study. The gels of desired specific gravity were prepared by adding $1.0 \mathrm{M}$ orthophosphoric acid solution. The solution was then transferred to glass test tubes ( $25 \mathrm{~mm}$ dia and $300 \mathrm{~mm}$ long). After the gels were set, the feed (lead nitrate) 
solutions of varying strengths $(0.25 \mathrm{M}$ to $2.0 \mathrm{M})$ in different modes were placed above the gels for crystallization. The chemical reaction employed for the growth of LNP single crystals in the silica gel media was

$$
4 \mathrm{~Pb}\left(\mathrm{NO}_{3}\right)_{2}+2 \mathrm{H}_{3} \mathrm{PO}_{4} \rightarrow \mathrm{Pb}_{4}\left(\mathrm{NO}_{3}\right)_{2}\left(\mathrm{PO}_{4}\right)_{2} \cdot 2 \mathrm{H}_{2} \mathrm{O}+6 \mathrm{HNO}_{3} \text {. }
$$

The chemicals used for LNP crystal growth were (i) BDH AnalaR lead nitrate $(98.2 \%)$ and (ii) BDH AnalaR aqueous orthophosphoric acid (98.5\%). Doubledistilled water was used throughout this study. The $\mathrm{pH}$ of gels before setting was kept constant at 3 throughout the investigation. To study the effect of temperature on the growth of LNP crystals, a constant temperature bath was used and the strength of lead nitrate was maintained at $1.0 \mathrm{M}$. A telescope moving horizontally and vertically was used for various measurements. The whole process took about 34 weeks (crystal size $12 \times 6 \times 3 \mathrm{~mm}^{3}$ ). The results, based on the statistical average of ten sets of experiments were quite consistent and reproducible. The grown crystals examined by chemical analysis, scanning electron microscope, X-ray diffraction, density measurements and thermogravimetric analysis confirmed that they were LNP crystals.

\section{Results and discussion}

\subsection{Effect of concentration of feed solution}

To investigate the effect of concentration of feed solutions, gels of same $\mathrm{pH}$ and density were prepared. Feed (lead nitrate) solutions of different concentrations varying from $0.25 \mathrm{M}$ to $2.0 \mathrm{M}$ were poured over the gels and kept undisturbed. The variation of nucleation density $N$ per $\mathrm{cm}^{2}$ with concentration of feed solution illustrated in figure 1 shows that at higher concentrations of feed solutions, because of the enhanced availability of $(\mathrm{Pb})^{2+}$ ions, the nucleation density increases. Higher

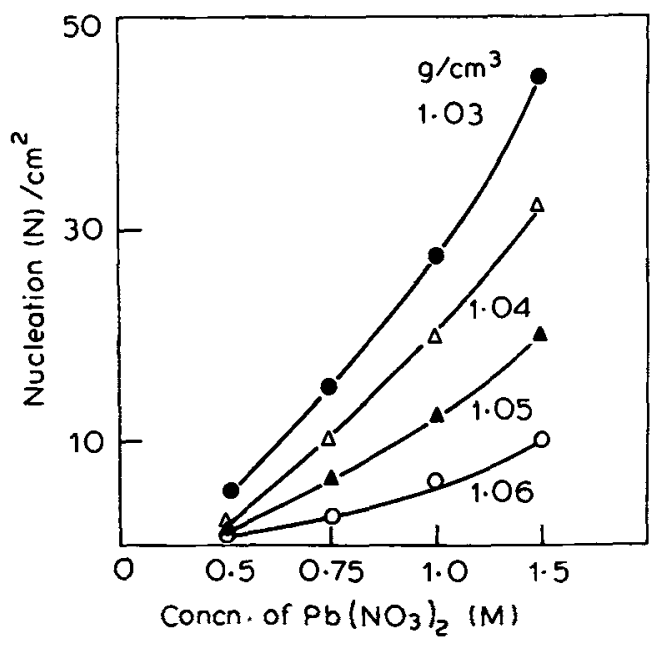

Figure 1. Nucleation density $N$ per $\mathrm{cm}^{2}$ against three different concentrations of lead nitrate solutions. 
concentration of feed solution gives rise to dendritic growth of LNP. This may he due to an increase in the supersaturation at higher concentration of lead nitrate solutions.

\subsection{Effect of gel density.}

The gels of different densities are obtained by mixing sodium metasilicate of specific gravity $1.03-1.06 \mathrm{~g} \mathrm{~cm}^{-3}$ with $0.25 \mathrm{M}$ to $2.5 \mathrm{M}$ lead nitrate solutions, keeping the $\mathrm{pH}$ at constant $3 \cdot 0$. The transparency of gel increases as the gel density decreases. Figure 2 is a plot of nucleation density $N$ vs the gel density. A greater gel density implies smaller pore size and poor communication among the pores and thus decreases the nucleation density (Halberstadt et al 1969). Increase in gel density also increases the contamination of the crystal with silica gel affecting the quality and shape of the crystals. The gel density of 1.03 gives good transparent LNP crystals but their size is small, while a density 1.05 to 1.06 gives translucent crystals. It may be noted that a gel density of 1.03 is the optimum value for the growth of welldefined single crystals of LNP.

\subsection{Effect of pH of gels}

The $\mathrm{pH}$ values of gels were set from 3 to 8 by the addition of orthophosphoric acid of various concentrations. As the $\mathrm{pH}$ increases, the transparency of gel decreases. Figure 3 shows that the nucleation density $N$ decreases with increase in $\mathrm{pH}$ value. Figure 4 represents LNP crystals grown in gel of $\mathrm{pH} 4.0$. LNP crystals grown at higher $\mathrm{pH}$ values are opaque and are poorly defined. This is due to the contamination of crystals by silica gels. The effect of $\mathrm{pH}$ in the dendritic growth of LNP crystals is discussed in detail in the following section.

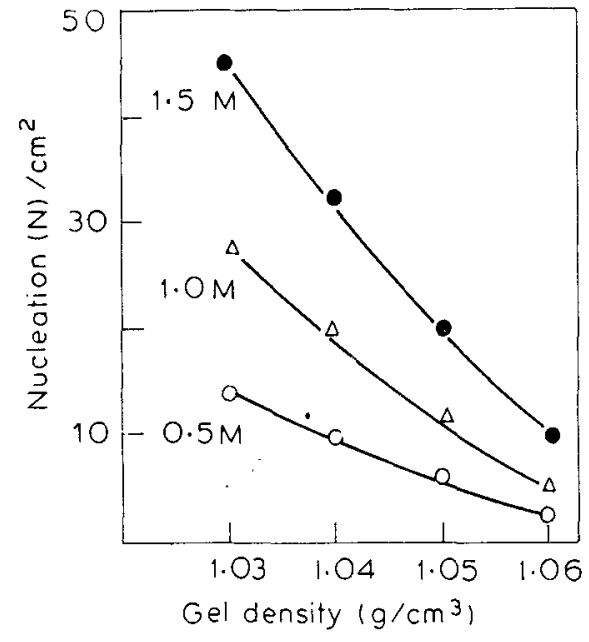

Figure 2. Nucleation density $N$ per $\mathrm{cm}^{2}$ vs gel density for three lead nitrate solutions.

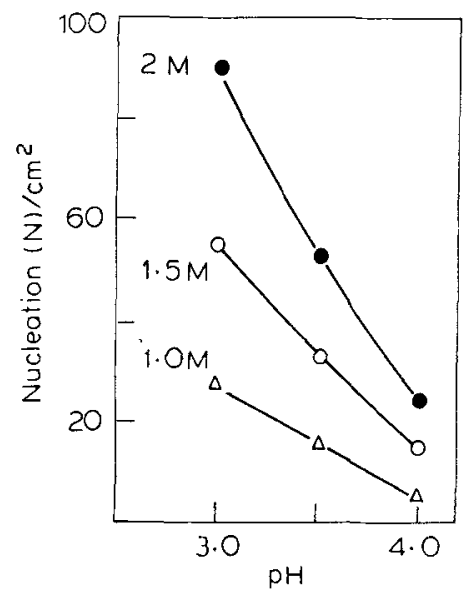

Figure 3. Nucleation density $N$ per $\mathrm{cm}^{2}$ against $\mathrm{pH}$ of gel solution for three different concentrations of lead nitrate solutions. 


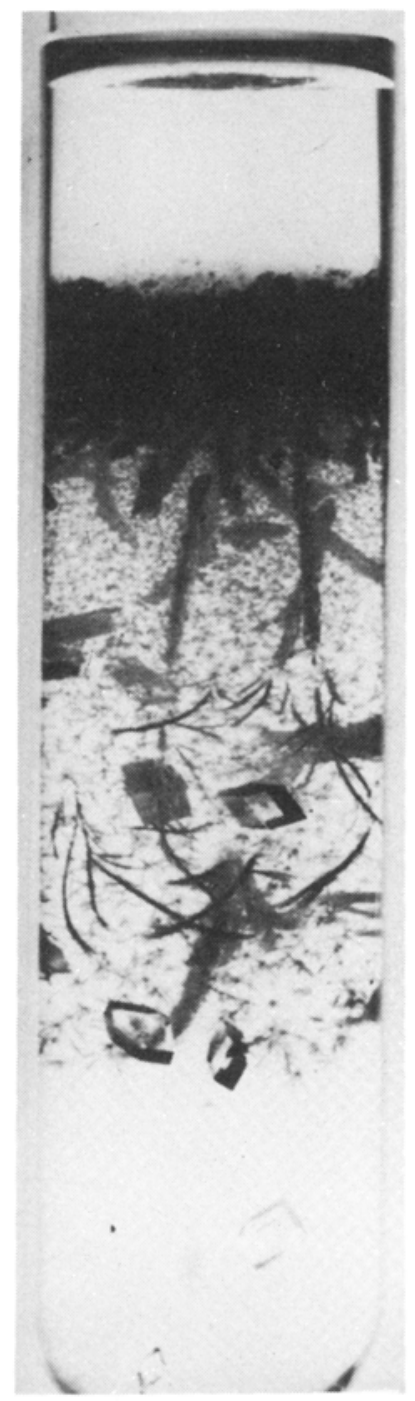

Figure 4. LNP crystals grown at pH 4 of gel solution.

\subsection{Effect of ageing of gels}

To investigate the effect of gel ageing, gels of same $\mathrm{pH}$ and density were allowed to age for various periods before adding the feed solution. Figure 5 is a plot of ageing vs the nucleation density $N$. As reported by Henisch et al (1965) gel ageing reduces the cell size and consequently the rate of diffusion $(\mathrm{Pb})^{2+}$ ions into the gel. It was observed that longer a gel sets at room atmosphere, greater the amount of water that evaporates out of the gel. The effect of water evaporation should be considered before and after the formation of gel framework. Before the gel is set, the evaporation of water causes an increase in gel density, which in turn decreases the diffusitivity of $(\mathrm{Pb})^{2+}$ ions in the gel thereby decreasing the number of nucleation 


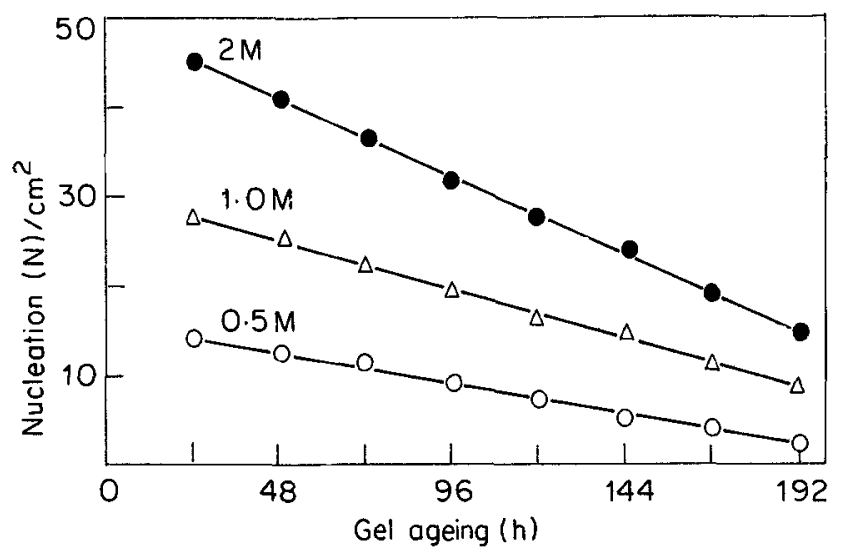

Figure 5. Nucleation density $N$ against gel ageing (h) for three concentrations of lead nitrate solutions.

sites. After the gel is set, evaporation of water causes not only the lack of ionic carriers in the channel of the gel frame-work, but also discontinuities in the channel due to shrinkage of gel. Both these effects would adversely affect the diffusion of $(\mathrm{Pb})^{2+}$ ions and hence the number of nucleation centres.

\section{Dendritic growth}

Most of the studies on dendritic growth deal with the growth kinetics and the dependence of dimensions of the growth conditions (Gilman 1963; Kotler and Tarshio 1968). Connections between the directions of the branch and the crystallographic directions have been discussed by Billing and Holmes (1953). Pendraza and Bolling (1975) observed that the most common growth morphology of arrayed dendritic growth was found in metals. It is well known that planar dendrites originate as a consequence of the solute build-up ahead of the gel interface for most thermal conditions.

The present results show that $\mathrm{pH}$ of the gel has considerable effect on the crystal growth. Irrespective of the concentration of feed solutions and gel densities, the LNP crystals grow only at a $\mathrm{pH}$ value of 4 and below. The $\mathrm{pH}$ ranging between 4.5 to 8.0 gave rise to dendritic growth only. The dendrites appear to be in poor alignment and it is quite possible that the different branches of dendrites were not strictly related to crystallographic directions. A possible explanation of this observation is that the nucleation centres originated were attracted together to form a near parallel dendritic growth (Buckley 1951) due to the high reaction rate between the reactants. Thus the dendritic growth was formed at a high reaction rate between lead nitrate and orthophosphoric acid solutions and at greater supersaturations with high concentration of feed solution.

The $\mathrm{pH}$ of gel was varied from 3 to 8 by the addition of orthophosphoric acid of various concentrations. As the $\mathrm{pH}$ decreased, the diffusion of ions increased; hence the growth rate increased (Liow and Faust 1977). This can be explained by the boxlike network structure of gel changing to a loosely bound platelet structure without cross-linkages and the cellular nature becomes less distinct, allowing the growth of LNP crystals. Figure 6 shows the effect of $\mathrm{pH}$ for the same gel density. Figure 7 


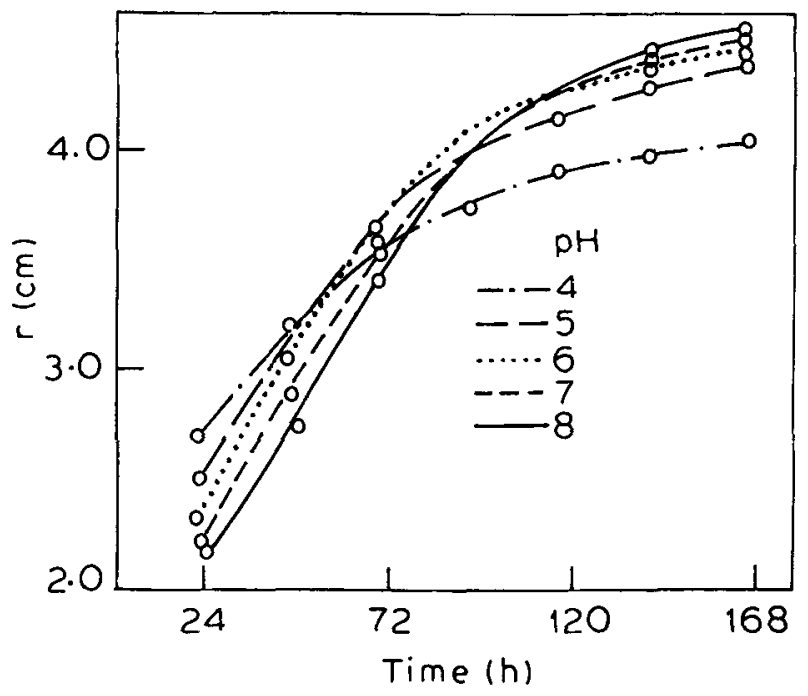

Figure 6. Length of dendrites $\gamma$ vs growth time $t$ for different $\mathrm{pH}$ values.

illustrates LNP dendrites growing at $\mathrm{pH}$ 6. From these figures, it is evident that in the low $\mathrm{pH}$ gels, the diffusion is greater and hence the length of dendrites is greater than that of high $\mathrm{pH}$ gels. For an ideal case, as the time lapses, the length of dendrites for lower $\mathrm{pH}$ gels should be higher than that of higher $\mathrm{pH}$ gels. But after some time (i.e. after 8 days), the growth of dendrites seized for lower $\mathrm{pH}$ gels, whereas for higher $\mathrm{pH}$ gels the dendritic growth increased further. This can be explained as follows: As the $\mathrm{pH}$ decreases, the gel medium becomes acidic and once the reaction starts, due to the byproduct $\left(\mathrm{HNO}_{3}\right)$, the $\mathrm{pH}$ still decreases making the medium more acidic. Initially, the dendritic growth is due to the high rate of reaction between the reactants, but after some time the acidic medium reduces the rate of reaction, thereby the dendritic growth becomes constant, facilitating LNP single crystals to grow. To grow good quality crystals the rate of reaction between reactants should be as low as possible. Thus the acidic medium reducing the rate of reaction between reactants favours growth of good LNP crystals in low $\mathrm{pH}$ gels. The two factors contributing to the growth rate constant $\left(K_{\text {effective }}\right)$, viz $K_{\text {kinetics }}$ and $K_{\text {diffusion }}$ constants is according to the relation (Laudise 1970)

$$
\frac{1}{K_{\text {effective }}}=\frac{1}{K_{\text {kinetics }}}+\frac{1}{K_{\text {diffusion }}} \text {. }
$$

Initially, the dendritic growth is due to the high reaction rate between the reactants,

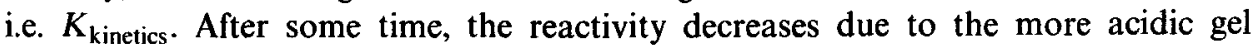
media and further growth is attributed to $K_{\text {diffusion. }}$. The growth rate constants for different $\mathrm{pH}$ values given in table 1 shows that as the $\mathrm{pH}$ decreases, $K_{\text {kinetics }}$ decreases and $K_{\text {difusion }}$ increases. Hence low $\mathrm{pH}$ gels favour good LNP single crystal growth. Increase in growth temperature increases the rate of reaction; hence $K_{\text {diffusion }}$ is dominated by $K_{\text {kinetics }}$ resulting in dendritic growth only. The effect of temperature is more predominant in high $\mathrm{pH}$ gels and high gel density than low $\mathrm{pH}$ gels and low gel density. In low gel density, the acidic medium which reduces the rate of reaction is compensated by the thermal energy of elevated temperatures. 


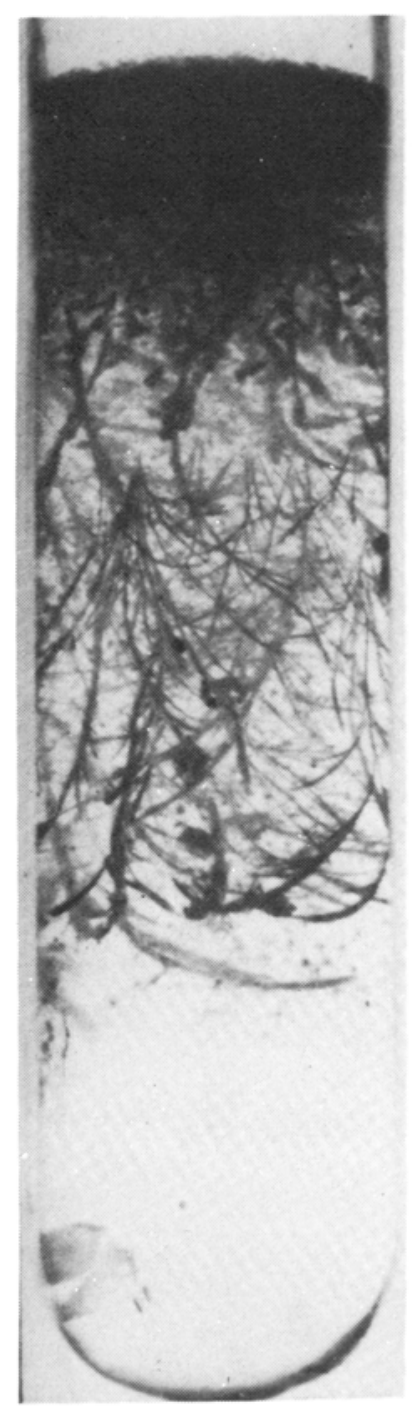

Figure 7. Dendritic growth of LNP at pH 6.

Table 1. Growth rate constants for various gel $\mathrm{pH}$

Growth rate constant ( $\left.K_{\text {effective }}\right)$ $\left(\mathrm{cm}^{2} / \mathrm{h}\right)$

\begin{tabular}{ccc} 
Gel pH & $K_{\text {dinetics }}$ & $K_{\text {diffusion }}$ \\
\hline 4 & $0 \cdot 1217$ & 0.0493 \\
5 & $0 \cdot 1481$ & 0.0466 \\
6 & $0 \cdot 1666$ & 0.0441 \\
7 & 0.1785 & 0.0375 \\
8 & $0 \cdot 1802$ & 0.0333 \\
\hline
\end{tabular}


Figure 8 illustrates the length of dendrites against growth time for different temperatures. The growth rate constant $K_{\text {kinetics }}$ determined from various feed solution concentrations is given in table 2. Figure 9 illustrates a plot of $K_{\text {kinetics }}$ against concentration of feed solution for different temperatures. It is seen from these figures that $K_{\text {kinetics }}$ increases with temperature resulting in dendritic growth only. The results reported here agree with those of a kinetic study of ionic crystals grown in gels by Henisch et al (1965).

\section{Crystal characterization}

Figure 10 shows some typical LNP crystals grown by the concentration programme. Electron microprobe and EDAX analysis of the grown LNP crystals confirmed the presence of lead, nitrate and phosphate ions. The lattice parameter of these crystals was determined by $\mathrm{X}$-ray rotation and Weissenberg diffraction patterns and was in excellent agreement with the values reported in literature (Bengstsson and Kemi 1941). The average density of the crystal was determined pyknometrically. The microhardness of these crystals was determined using Vickers hardness indentor. The Young modulus of these crystals was determined using INSTRON compressing testing machine. The magnetic susceptibility of the crystals was measured using a Faraday Gouy balance method. The perfection properties of

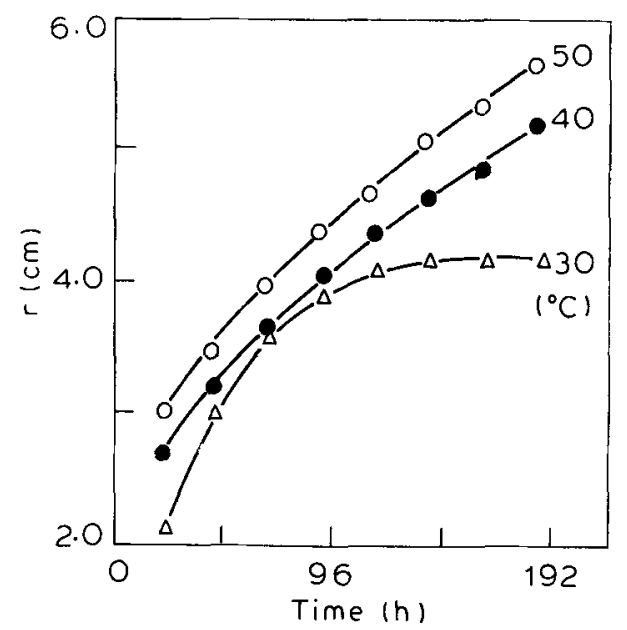

Figure 8. Dendritic length $\gamma$ against growth time $t$ for different temperatures.

Table 2. Growth rate constants for various feed solution concentrations.

\begin{tabular}{cccc}
\hline & \multicolumn{3}{c}{$\begin{array}{l}\text { Growth rate constant } K_{\text {kinetics }}\left(\mathrm{cm}^{2} / \mathrm{h}\right) \text { for } \\
\text { different concentrations of feed solutions }\end{array}$} \\
\cline { 2 - 4 } $\begin{array}{c}\text { Growth } \\
\text { temperature }\left({ }^{\circ} \mathrm{C}\right)\end{array}$ & $1.0 \mathrm{M}$ & $1.5 \mathrm{M}$ & $2.0 \mathrm{M}$ \\
\hline 30 & 0.1350 & 0.1666 & 0.1426 \\
40 & 0.1837 & 0.2206 & 0.3030 \\
50 & 0.2204 & 0.2816 & 0.3751 \\
\hline
\end{tabular}




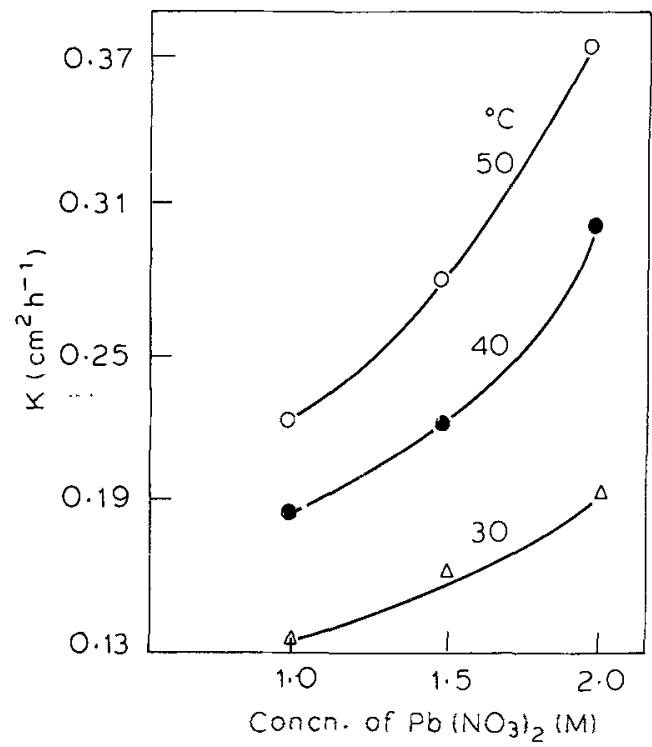

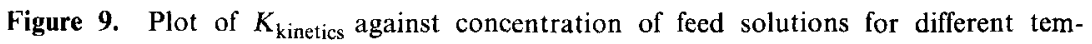
peratures.

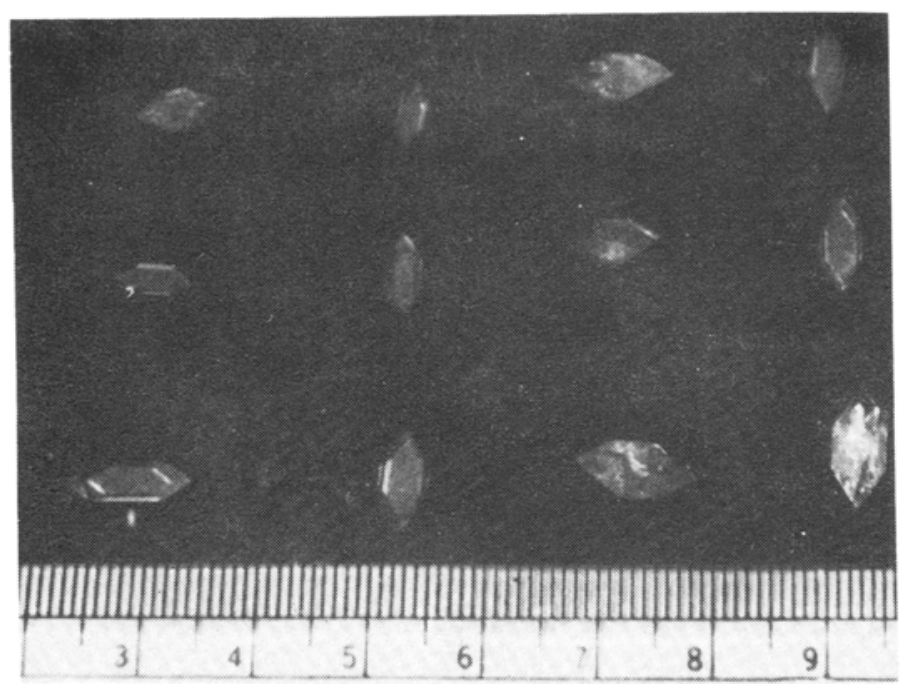

Figure 10. LNP crystals grow $n$ by concentration programming.

these crystals were studied by employing chemical etching technique. Table 3 gives one of the properties of these LNP crystals.

\section{Conclusions}

(i) Silica gels are suitable for growing transparent and high quality LNP crystals. (ii) Nucleation control can be achieved by changing a variety of gel parameters 
Table 3. Properties of LNP single crystals.

\begin{tabular}{|c|c|}
\hline Properties & Data \\
\hline Maximum size obtained & $12 \times 6 \times 3 \mathrm{~mm}^{3}$ \\
\hline Crystals morphology & Prismatic platelets \\
\hline Faces developed & $\{100\},\{010\},\{011\},\{230\}$ \\
\hline \multirow[t]{3}{*}{ Unit cell dimensions } & $a=19.5111 \AA, b=7.37 \AA$ \\
\hline & $c=10.94 \AA, x=\eta=90^{\circ}$ \\
\hline & $\beta=113^{\circ}$, Monoclinic \\
\hline Space group & $\mathrm{P} 2_{1} / \mathrm{C}$ \\
\hline Number of molecules per unit cell & 4 \\
\hline Pyknometric density & $5 \cdot 44 \mathrm{~g} \mathrm{~cm}^{-3}$ \\
\hline Vickers hardness numerals & $10-15$ \\
\hline Young modulus & $1.531 \times 10^{9}$ dynes $\mathrm{cm}^{-2}$ \\
\hline Magnetic susceptibility & $8.7364 \times 10^{-6} \mathrm{em} \mathrm{u}$ \\
\hline Cleavage plane & $1001)$ \\
\hline Estimated dislocation density & $7 \times 10^{2} \mathrm{~cm}^{-2}$ \\
\hline Polarization & $\begin{array}{l}\text { Crystals do not show spontaneous pola- } \\
\text { rization }\end{array}$ \\
\hline
\end{tabular}

such as concentration of feed solution, gel density, gel pH, ageing of gels, etc. (iii) Relatively greater concentrations of $\left(\mathrm{NO}_{3}\right)_{2}^{-}\left(\mathrm{PO}_{4}\right)_{2}^{-}$ions produces clearer LNP crystals while greater $\left(\mathrm{Pb}_{4}\right)^{2+}$ ion concentration produces opaque LNP crystals. (iv) Gel growth experiments produce LNP dendrites and perfect LNP single crystals.

\section{Acknowledgements}

The authors thank CSIR, New Delhi for financial assistance. One of the authors (CCD) thanks Mr Padmanabh Amin and Mrs Dolly Amin (Naandanvan Shilipi Society, Nadiad) for their interest and encouragement.

\section{References}

Armington A F and O'Conner J J 1967 Mater. Res. Bull. 2907

Bengstsson E and Kemi A 1941 Mineral (Geolo) 15B 1

Brenner W, Blank Z and Okamoto Y 1966 Nature (London) 212392

Brezina B and Horvath J 1982 J. Cryst. Growth 52858

Billing M E and Holmes P J 1953 Acta Crystallogr. 8353

Buckley H E 1951 Crystal growth (New York: John Wiley)

Dennis J and Henisch H K 1967 J. Electrochem. Soc. 114263

Halberstadt E S, Henisch H K, Nickel J and White E W 1969 J. Colloid Interface Sci. 29469

Henisch H K, Dennis J and Hanoka J J 1965 J. Phys. Chem. Solids 26493

Henisch H K, Hanoka J J and Dennis J 1965 J. Electrochem. Soc. 112627

Henisch H K 1970 Crystal growth in gels (Pennsylvania: University Press)

Gilman J J 1963 The art and science of growing crystals (New York: John Wiley)

Glockber D A and Soest J E 1969 J. Chem. Phys. 73143

Kotler G R and Tarshio L A 1968 J. Cryst. Growth 3/4 603

Kratochvil P, Sprusil B and Heyrovsky M 1968 J. Cryst. Growth 3/4 360

Liow H M and Faust J W Jr 1977 J. Cryst. Growth 13/14 471

Laudise R A 1970 The growth of single crystals (New York: Prentice Hall)

Pendraza O and Bolling G F 1975 J. Cryst. Growth 28311

Ruiz J M G and Cintas E D A 1985 Mater. Res. Bull. 20x 1157 